\title{
Role of Self-Efficacy and Negative Perfectionism in the Prediction of Procrastination of Narcissistic Personality: A Study on Non-Clinical Subjects
}

\author{
Hamed Jabbari Ghazi Jahani ${ }^{\text {a* }}$, Azadeh Ehsanikenari ${ }^{a}$, Afsaneh Sadat Sharif ${ }^{\text {a }}$ \\ ${ }^{a}$ Department of Personality Psychology, Science and Research Branch, Islamic Azad University, Tehran, Iran
}

\begin{abstract}
The present research was performed to investigate the role of self-efficacy and negative perfectionism in the prediction of procrastination of narcissistic personality. This is a descriptive research of correlational type for which performance a total of 412 students were selected via random multi-stage sampling method. In order to examine the research hypothesis and accomplish the research objective, the participants were provided with a questionnaire composed of Narcissistic Personality Inventory 16, General Procrastination Scale, General Self-Efficacy Scale, and Positive and Negative Perfectionism Scale. Collected data were analysed using descriptive statistics, Pearson's correlation coefficient, and stepwise multiple regression. Results of the research indicated significant associations between self-efficacy, negative perfectionism, and narcissism, in one hand, and procrastination, on the other hand, so that, as variables, self-efficacy, negative perfectionism, and narcissism could explain $10 \%$ of the variance in procrastination. Results of the present research indicated the importance of self-efficacy, negative perfectionism, and narcissism in the development and exacerbation of procrastination, and placed an emphasis on the necessity of paying attention to the role of such effective antecedents by mental health-related authorities, so as to reduce procrastination.
\end{abstract}

\section{Keywords:}

Perfectionism; Self-Efficacy;

Narcissistic Personality;

Procrastination.

Article History:

Received: 18 September 2018

Accepted: 04 December 2018

\section{1- Introduction}

In clinical context, narcissism is characterized by such traits as grandiosity, mental involvement with fantasies of unlimited success, power, talent, and beauty, belief in being an outstanding and special person [1, 2], sense of omnipotence, tendency toward colonialism in inter-personal relationships, lack of empathy and need for extreme praise [3-5], self-esteem dysregulation with self-enhancement, which serves to protect and support a grandiose but fragile self and to avoid underlying inferiority, and negative experiences and feelings of the self $[3,6,7]$.

Despite their numerous similarities, clinical and non-clinical concepts of narcissism are distinctive in one important aspect [8]. In clinical context, narcissism is studied as a personality disorder, and individuals may be identified as being engaged with narcissistic personality disorder based on a series of criteria [9]. In contrast, in non-clinical context, narcissism is considered as a dimension and continuum from normal to narcissistic. In such structure of narcissism, there exists no point along the narcissism continuum where one shifts from normal to narcissist [8, 10]. In other words, the same traits that can constitute normal part of personality may end up creating significant social, professional, and psychological disorders should those are conflicting and/or accompanied with defects in self-regulation ability, thereby urging for clinical considerations [11-13].

Procrastination is a widespread potentially harmful phenomenon that refers to the voluntarily delaying an intended and necessary and/or [personally] important activity, despite expecting potential negative consequences that outweigh the positive consequences of the delay $[14,15]$. Procrastination is a prevalent behavior trait [16], prevalence rates for

\footnotetext{
*CONTACT: Info@hamedjabbari.com

DOI: http://dx.doi.org/10.28991/esj-2018-01158

(C) This is an open access article under the CC-BY license (https://creativecommons.org/licenses/by/4.0/).
} 
procrastination ranging between $15 \%-20 \%$ in the general adult population prove as evidence for the frequency of this phenomenon [17-20]. Procrastination is a failure of self-regulation [16, 21-23], in other words, it has been viewed as a maladaptive attempt to manage behavior or emotion [24, 25], that is associated with various mental health problems [26]. Procrastination increases negative feelings such as shame or guilt [27], reduces well-being [20], and affects health behavior, such as deferring to seek proper care for health problems [28]. Moreover, people with high level of procrastination show an intensified risk for the development, maintenance, and aggravation of mental disorders such as anxiety disorders and depression [29, 30]. Furthermore, Studies found links between procrastination and low selfefficacy [31,32], low self-esteem [23], and dependency on others, and defeating behaviors [33].

Self-efficacy refers to an individual's judgement about his/her own ability to achieve his/her goals, and to predict the required competences in terms of making effort, diligence, accomplishing tasks, and implementation of the required solutions to reach the goals [34-37]. Introduced in Bandura's (1977) theory, this concept plays a key role in determining individuals' attitudes, feelings, and behavior in various situations [38, 39]. Individuals enjoying high senses of selfefficacy opt for and then exhibit a deep commitment to challenging goals and problems [40]. When dealing with a failure, being well self-confident, these individuals tend to see obstacles as addressable, adopt further strategies to cope with problems, attempt to reach desired outcomes, and experience lower levels of stress and anxiety [41, 42]. Conversely, individuals with low senses of self-efficacy tend to avoid confronting any obstacle rather than addressing them; they quite easily quit and usually fail to exhibit any resistance and robustness. When dealing a problem, these individuals tend to concentrate on their failures and negative outcomes, rather than searching for possible workarounds, and hence become depressed readily $[43,44]$. Therefore, individuals with higher levels of self-efficacy can better adapt to environmental circumstances and are more successful in communicating with others [37, 39].

Perfectionism is another psychological variable that exhibits a significant relationship with procrastination [45-48]. Perfectionism is, indeed, a personality construct characterized with such traits as attempting toward being complete and perfect, setting extreme performance criteria, and tendency toward critical evaluation [49-51]. Based on the Hamachek's (1978) classification of perfectionism into normal and abnormal and within the framework of a theoretical model, TerryShort, Glynn Owens, Slade, and Dewey (1995) distinguished between two types of perfectionism, namely positive and negative perfectionism. Positive perfectionism encompasses those aspect of perfectionism which are related to excellent yet realistic personal criteria, tendency toward discipline and organization, sense of satisfaction with self-performance, search for excellence, and motivation toward achieving positive rewards [51-54]. This dimension of perfectionism is correlated to indicators of good adjustment such as positive affect [55], better interpersonal relationships and performance $[50,56]$. At the other end of the spectrum, negative perfectionism involves those aspects of perfectionism which are related to unrealistically high standard levels, worries about mistakes, sense of conflict between expectations and achievement, and critical evaluation of self-performance [51, 53, 57]. This dimension of perfectionism is known to be correlated to indicators of conflict, such as anxiety [49], depression [58], and negative affect [59].

Considering the significance of narcissism as a personality style in psychological studies, and given the promotion of narcissistic behavior across today's societies, the present research seeks, in the form a novel research based on existing experimental and theoretical works, to provide health experts and therapists with some information on consequences of narcissism, so as to draw a more accurate and comprehensive image of narcissism and use it to enhance the level of individuals' mental health. Therefore, based on what was mentioned so far, the present research aims at investigating the role of self-efficacy and negative perfectionism in the prediction of procrastination of narcissistic personality.

\section{2- Method}

\section{2-1- Participants and Procedure}

In terms of variable type and data gathering methodology, the present research is a descriptive-correlational study. Statistical population of this research was composed of all students studying at Science and Research Branch of Islamic Azad University (Tehran, Iran) in spring semester 2018 (about 50,000 students). Using Morgan's formula, sample size was calculated as 381 students, but considering various reasons such as omission of subjects, the final sample was composed of 537 students who were selected from the statistical population via random multi-stage sampling. For this purpose, among the total of 20 faculties administered by the university, four were selected (i.e. faculties of Humanities, Basic Sciences, Engineering, and Medical Sciences). Then, five classes in each faculty were selected randomly and all of the students in the selected classes were participated in the research as subjects $(n=537)$. Once finished with collecting questionnaires, 125 cases were omitted due to incompleteness, ending up with a reduced research sample size of 412. Figure 1 illustrates the participant flow through the study. 


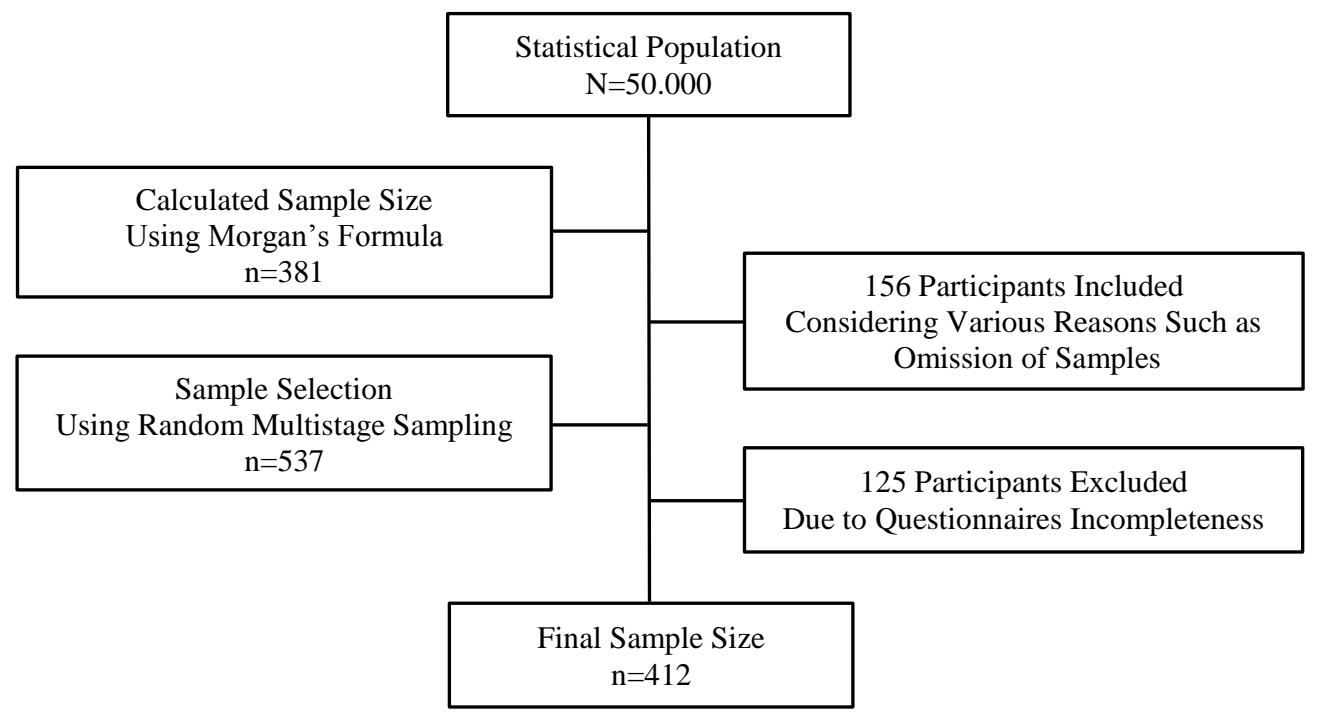

Figure 1. Participant Flow Chart.

\section{2-2- Measures}

\section{2-2-1- Narcissistic Personality Inventory-16 (NPI-16)}

This 16-item inventory is a shortened version of the original 40-item narcissistic personality inventory which was constructed by Ames, Rose, and Anderson (2006) to evaluate narcissistic personality-related traits. This inventory has no sub-scale and evaluates narcissism following a one-dimensional approach. In terms of response range, each item in this inventory has a pair of items of which the respondent shall select one. For each item selected from the row A or B, a score of 1 or 0 is considered, respectively. Overall score of inventory is then calculated as sum of scores of all items. Accordingly, each subject ends up with a score between 0 and 16. Higher scores indicate higher levels of narcissism exhibited by the subject, and vice versa [60]. In Iran, Mohammadzadeh (2010) performed a cross-sectional survey study where he tested this inventory on 342 students. Accordingly, correlation coefficient between NPI-16 and Millon Clinical Multiaxial Inventory-II scores was found to be 0.77 , proving discriminant validity of the inventory. Furthermore, testretest reliability coefficient, correlation coefficient of split-half reliability determination, and Cronbach's coefficient alpha in internal consistency measurement were calculated to be $0.84,0.74$, and 0.79 , respectively [61].

\section{2-2-2- General Procrastination Scale (GPS)}

Constructed by Lay (1986), this 20-statement scale is used to evaluate general procrastination utilizing a 5-point Likert scale ranging from 1 (extremely uncharacteristic) to 5 (extremely characteristic). In this scale, statements 3 , 4, 6, $8,11,13,14,15,18$, and 20 are scored reversely, and overall score is obtained as the sum of all scores assigned to all statements. As far as this scale is concerned, a subject may end up with any score between a minimum of 20 and a maximum of 100. A higher overall score indicates higher procrastination and vice versa. Reportedly, this scale exhibits good validity and reliability [62, 63]. In their research, Ferrari, Johnson, and McCown (1995) confirmed construct validity and predictive validity of this scale [64]. In Iran, Hosseini and Khayyer (2009) used principal components analysis as a factor analysis technique to examine validity of this instrument and obtained a Kaiser-Meyer-Olkin (KMO) coefficient of .78 and Chi score (as calculated per Bartlett test) of 778.80, which was statistically significant. In addition, following internal consistency method, reliability of this instrument was investigated and a Cronbach's coefficient alpha of .80 was reported [65].

\section{2-2-3- General Self-Efficacy Scale (GSE-10)}

The 20-item German version of this scale was constructed by Schwarzer and Jerusalem in 1979 to evaluate general and social self-efficacy [66]. Later on, the two researchers evaluated the scale and reduced its items to 10 and obtained a scale whose all of items measured general self-efficacy. GSES-10 was translated into Persian by Nezami, Schwarzer, and Jerusalem (1996) [67]. The items were scored based on a 4-point Likert scale ranging from 1 (not at all true) to 4 (exactly true), so that each subject could obtain an overall score between 10 and 40 . This scale has adequate validity and reliability. Examining students in Spain, Germany, and China, Schwarzer, Bäßler, Kwiatek, Schröder, and Zhang (1997) obtained internal consistency coefficients of different versions of GSES-10 as 0.81, 0.84, and 0.91, respectively [68]. In Iran, Rajabi (2006) examined reliability and validity of GSES-10 on students and obtained a Cronbach's coefficient alpha of 0.82; furthermore, when evaluated against Rosenberg's self-esteem scale, its concurrent validity coefficient was found to be 0.30 [69]. 


\section{2-2-4- Positive and Negative Perfectionism Scale (PANPS)}

This 40-statement scale was developed by Terry-Short et al. (1995) Out of the 40 statements, 20 statements evaluate positive perfectionism while the other statements examine negative perfectionism. This scale is scored based on a 5point Likert scale ranging from 1 (strongly disagree) to 5 (strongly agree), so that the subject may end up with a score between 20 and 100 for each of the positive and negative perfectionism scales [53]. In the Persian form of this scale, Cronbach's alpha of each sub-scale on a sample composed of 212 students was found to be 0.90 and 0.87 when all of the subjects were considered. The corresponding values to girls only were 0.91 and 0.88 , respectively, while those of boys only were 0.89 and 0.86 , respectively, indicating high internal consistency of this scale. Correlation coefficient among the scores attained by 90 subjects at two stages spaced by four weeks was $r=0.86$ for all of the subjects, $r=$ 0.84 for girls only, and $r=0.87$ for boys only, indicating satisfactory test-retest reliability of this scale. Validity of the positive and negative perfectionism questionnaire was investigated by calculating correlation coefficients between subscales of this test and those of General Health Questionnaire [70] and Coopersmith's Self-Esteem Inventory [71] via principal components analysis. Accordingly, coefficients of correlation between positive and negative perfectionism sub-scales, in one hand, and somatic symptoms (-0.32 and 0.33 , respectively), anxiety/insomnia ( -0.41 and 0.39 , respectively), social dysfunction ( -0.54 and 0.57 , respectively), depression ( -0.58 and 0.63 , respectively), and overall score of General Health Questionnaire (-0.46 and 0.48, respectively), on the other hand, were calculated. Furthermore, coefficients of correlation between sub-scales of positive and negative perfectionism and self-esteem were found to be 0.44 and -0.52 , respectively [72].

\section{3- Results}

In the present research, $58 \%$ (238 individuals) and 42\% (174 individuals) of the subjects were women and men, respectively, $\left(M_{\text {age }}=32.40\right.$ years, age range: $19-46$ years). In addition, $73 \%$ (300 individuals) and $27 \%$ ( 112 individuals) of the subjects were undergraduate and post-graduate students, respectively. Table 1 presents descriptive statistics and the results of Pearson's correlation coefficient between the research variables.

Table 1. Descriptive Statistics and Correlations.

\begin{tabular}{ccccccc}
\hline Variables & M & SD & $\mathbf{1}$ & $\mathbf{2}$ & $\mathbf{3}$ & $\mathbf{4}$ \\
\hline Narcissism & 8.82 & 3.65 & 1 & & & \\
Procrastination & 48.16 & 14.18 & $0.185^{* *}$ & 1 & & \\
Self-Efficacy & 25.83 & 7.77 & $-0.196^{* *}$ & $-0.221^{* *}$ & 1 & \\
Negative Perfectionism & 45.14 & 12.43 & $0.204^{* *}$ & $0.207^{* *}$ & -0.011 & 1 \\
\hline
\end{tabular}

Note. **. Correlation is significant at the 0.01 level (2-tailed).

According to Table 1, as far as the subjects of this research were concerned, a significant and positive relationship was indicated between narcissism and procrastination $(r=0.185, p<0.01)$, a significant and negative relationship was indicated between self-efficacy and procrastination $(r=-0.221, p<.01)$, and a significant and positive relationship was identified between negative perfectionism and procrastination $(r=0.207, p<0.01)$. In order to determine contributions of perfectionism and self-efficacy in the prediction of procrastination of a narcissist personality, stepwise multiple regression technique was used. Table 2 provides a summary of the results of regression model of the variables considered in this study.

Table 2. Summary of Regression Analysis Results.

\begin{tabular}{|c|c|c|c|c|c|c|c|c|c|c|}
\hline Modal & Predictors & $R$ & $R^{2}$ & Adjusted $R^{2}$ & $F$ & Sig. & $B$ & Beta & $t$ & Sig. \\
\hline 1 & Self-Efficacy & 0.221 & 0.049 & 0.047 & 21.150 & 0.000 & -0.404 & -0.221 & -4.599 & 0.000 \\
\hline \multirow[b]{2}{*}{2} & Self-Efficacy & \multirow[b]{2}{*}{0.301} & \multirow[b]{2}{*}{0.091} & \multirow[b]{2}{*}{0.086} & \multirow[b]{2}{*}{20.402} & \multirow[b]{2}{*}{0.000} & -0.400 & -0.219 & -4.649 & 0.000 \\
\hline & $\begin{array}{c}\text { Negative } \\
\text { Perfectionism }\end{array}$ & & & & & & 0.233 & 0.204 & 4.329 & 0.000 \\
\hline \multirow{3}{*}{3} & Self-Efficacy & \multirow{3}{*}{0.319} & \multirow{3}{*}{0.102} & \multirow{3}{*}{0.095} & \multirow{3}{*}{15.392} & \multirow{3}{*}{0.000} & -0.361 & -0.198 & -4.138 & 0.000 \\
\hline & $\begin{array}{c}\text { Negative } \\
\text { Perfectionism }\end{array}$ & & & & & & 0.208 & 0.182 & 3.796 & 0.000 \\
\hline & Narcissism & & & & & & 0.423 & 0.109 & 2.231 & 0.026 \\
\hline
\end{tabular}

Note. Dependent Variable: Procrastination.

According to Table 2, in the first step, self-efficacy could explain 5\% of the variance in procrastination of the subjects. In the second step, self-efficacy and negative perfectionism could explain a total of $9 \%$ of the variance in procrastination of the subjects. Finally, in the third step, self-efficacy, negative perfectionism and narcissism could describe $10 \%$ of the variance in procrastination of the subjects. Results of the so-called analysis of variance (ANOVA) on the first $(F(1,410)$ 
$=21.150, p<0.0005$, Adjusted $\left.R^{2}=0.047\right)$, second $\left(F(2,409)=20.402, p<0.0005\right.$, Adjusted $\left.R^{2}=0.086\right)$, and third $\left(F(3,408)=15.392, p<0.0005\right.$, Adjusted $\left.R^{2}=0.095\right)$ model were indicative of significance of all results. Furthermore, based on the obtained values of Beta, self-efficacy (Beta $=-0.198)$ played the most effective role in the prediction of the subjects' procrastination, followed by negative perfectionism $($ Beta $=0.182)$ and then narcissism $($ Beta $=0.109)$.

\section{4- Discussion}

The present research was performed to investigate the role of self-efficacy and negative perfectionism in the prediction of procrastination of narcissistic personality. Indicating a significant and negative relationship between selfefficacy and procrastination, findings of this research were in agreement with those of previous research works $[25,31$, $32,73,74]$. For instance, based on the findings reported by Wäschle, Allgaier, Lachner, Fink, and Nückles (2014), selfefficacy mediates the effect of perceived goal achievement on procrastination, and students with low perceived selfefficacy are vulnerable for finding themselves in a vicious circle of procrastination [32].

Individuals with high perceived self-efficacy are well confident about their abilities for accomplishing tasks properly and exhibit adequate deals of interest and tendency [40]. Furthermore, fear of failure, shyness, unstable self-esteem, and lack of courage, which are among the characteristics of procrastination, are less observed among such individuals [16, $23,24,30,36,37]$. Persons with higher perceived self-efficacy are more successful in accomplishing tasks, feel empowered in difficult situations, and receive the required encouragements from others [34, 35, 39], which further adds to their self-efficacy and attenuates procrastination [31,32]. On the other hand, should an individual frequently doubts about his/her own capabilities for undertaking a particular task under various circumstances, at some point, he/she will start to develop the unrealistic belief that he/she is not capable of successfully accomplishing any task [43, 44]. In such a case, the individual no more feels any internal control over events, thereby perceiving activities as difficult as he/she is not capable of practicing them $[34,35,37,39,40]$.

Moreover, results of the present research showed that there is a significant and positive relationship between negative perfectionism and procrastination. This was in line with findings of previous research works [45-48]. For instance, based on the findings reported by Smith, Sherry, Saklofske, and Mushqaush (2017), perfectionistic concerns had a moderate positive association with procrastination, and perfectionistic concerns generate a persistent paralytic gap between the actual and the ideal self that contributes to procrastinatory behavior [48].

Maladaptive perfectionism is significantly associated with worry, fatigue, pessimism, reduced performance, and lack of perceived self-control; these findings correspond to characteristics of those exhibiting procrastinatory behavior [16, $20,23,30,49]$. Also, perfectionists are known to have unreasonable beliefs and extreme fear of failure; this fear encourages them to exhibit procrastinatory behavior in important situations, so as to decrease their anxiety [21, 50, 51]. In other words, those individuals who set forth unrealistically high standards for themselves, feel extremely worried about their mistakes and personal imperfections, and perceive a large gap between their self-performance and personal standards are vulnerable to negative expectations and senses of frustration and failure [49, 51, 57-59]; such negative senses then result in compulsory-like doubts in various tasks and keeps them from accomplishing personalized functions in a timely manner while providing a basis for further tendency toward procrastination $[45,47,48]$.

Another finding of this research revealed a positive and significant association between narcissistic personality traits and procrastination. This finding was in agreement with explanations presented in some of the research works performed in this scope [75-77]. Regarding antecedents of procrastination, researchers and theorists have referred to various factors such as low self-esteem [23], dependence on others and self-disabling behaviors [33], fear of negative appraisal [19], learned helplessness [29], inferiority complex, fear of failure, low tolerance and anger [16, 21, 23, 78], negative feelings such as shame and guiltiness [27], wishful thinking [77], and tendency toward depression and neuroticism [30]. Narcissistic personality exhibits similar traits. For instance, failure of regulating self-esteem makes narcissistic persons so sensitive to critic- or failure-resulted damages [7,79], and associated continuous senses of shame, humiliation, and self-criticism lead them toward social withdrawal, depressed mood, and disordered performance $[3,6,13]$. This is on this basis that one can explain the correlation between procrastination and narcissistic personality traits. In addition, results of the present research showed that, altogether, self-efficacy (via a significant negative association), perfectionism, and narcissism (via significant positive associations) can explain 10\% of the variance of procrastination.

The results of the present study indicated the importance of self-efficacy, negative perfectionism, and narcissism in the development and exacerbation of procrastination. Therefore, positive beliefs about the ability to properly carry out assignments, the constructive skill of dealing with issues despite multiple problems, and having realistic personal criteria for organizing and applying a set of actions to achieve the desired level of performance, persuade individuals to confront the challenges of life and gain valuable experiences, which increases the ability of the individual, and brings positive outcomes in different aspects of life.

The present research suffered from particular limitations, by addressing which in future studies one may achieve more comprehensive results. Among others, a limitation of this research was non-clinical nature of the subjects 
participating the research; accordingly, the presented results can be generalized to clinical populations only with care. Furthermore, given that the roles of demographic variables such as gender, age, education level, and marital status were not taken into consideration, there are chances that these variables affect the results undesirably. Self-reporting nature of the questionnaire used to evaluate the traits related to narcissistic personality was another limitation faced by this research. It is suggested to undertake more extensive research on larger samples, sample subjects from clinical patients, and perform similar research works on other personality styles. Based on the results of the present research, educational authorities are recommended to, with high priority, provide appropriate environmental conditions and facilities and hold workshops for enhancing self-efficacy and positive perfectionistic traits, i.e. making effort and competition for progress, self-esteem, and self-flourishing among students. Furthermore, given the antecedents referred to in relation to procrastination (e.g. anxiety, depression, fear of negative appraisal, low self-esteem, fear of failure, negative perfectionism, and narcissistic personality traits), the authorities involved with students' mental health shall further undertake to identify and investigate the antecedents contributing to procrastination, so as to be able to take the required interventions on time.

\section{5- Acknowledgments}

The students who participated as subjects in this research, and also officials of the faculties of Humanities, Basic Sciences, Engineering, and Medical Sciences at Science and Research Branch of Islamic Azad University (Tehran, Iran) are whole-heartedly appreciated for their close collaboration with this project.

\section{6- Funding}

The authors received no financial support for the research, authorship, and/or publication of this article.

\section{7- Conflict of Interest}

The authors declare no conflict of interest.

\section{8- References}

[1] Lamkin, J., J. A. Lavner, and A. Shaffer. "Narcissism and observed communication in couples." Personality and Individual Differences 105, (2017): 224-228. doi: 10.1016/j.paid.2016.09.046.

[2] Zeigler-Hill, V., and D. R. C. Trombly. "Narcissism and mate value: Is beauty in the eye of the narcissistic beholder?" Personality and Individual Differences 122, (2018): 115-119. doi: 10.1016/j.paid.2017.10.021.

[3] Kealy, D., J. S. Ogrodniczuk, S. M. Rice, and J. L. Oliffe. "Pathological narcissism and maladaptive self-regulatory behaviours in a nationally representative sample of Canadian men.” Psychiatry Research 256, (2017): 156-161. doi: 10.1016/j.psychres.2017.06.009.

[4] Ronningstam, E. "Narcissistic personality disorder: a clinical perspective." Journal of Psychiatric Practice 17, no. 2 (2011): 8999. doi: 10.1097/01.pra.0000396060.67150.40.

[5] Wardecker, B. M., W. J. Chopik, O. P. LaBelle, and R. S. Edelstein. "Is narcissism associated with baseline cortisol in men and women?" Journal of Research in Personality 72, (2018): 44-49. doi: 10.1016/j.jrp.2016.07.006.

[6] Ogrodniczuk, J. S. (Ed.). “Understanding and treating pathological narcissism.” Washington, DC, US: American Psychological Association, (2013). doi: 10.1037/14041-000.

[7] Ronningstam, E. "Beyond the diagnostic traits: A collaborative exploratory diagnostic process for dimensions and underpinnings of narcissistic personality disorder." Personality Disorders: Theory, Research, and Treatment 5, no. 4 (2014): $434-438$. doi: $10.1037 /$ per0000034.

[8] Foster, J. D., and W. K. Campbell. "Are there such things as "Narcissists" in social psychology? A taxometric analysis of the Narcissistic Personality Inventory." Personality and Individual Differences 43, no. 6 (2007): 1321-1332. doi: $10.1016 /$ j.paid.2007.04.003

[9] Carroll, P. J., R. M. Arkin, and A. L. Wichman. (Eds.). "Handbook of Personal Security.” New York, NY, US: Psychology Press, (2015).

[10] Widiger, T. A. "In defense of narcissistic personality traits." Personality Disorders: Theory, Research, and Treatment 1 , no. 3 (2010): 192-194. doi: 10.1037/a0020199.

[11] Miller, J. D., and W. K. Campbell. “Comparing clinical and social-personality conceptualizations of narcissism.” Journal of Personality 76, no. 3 (2008): 449-476. doi: 10.1111/j.1467-6494.2008.00492.x.

[12] Miller, J. D., and W. K. Campbell. "The case for using research on trait narcissism as a building block for understanding narcissistic personality disorder." Personality Disorders: Theory, Research, and Treatment 1, no. 3 (2010): 180-191. 
doi: $10.1037 / \mathrm{a} 0018229$.

[13] Pincus, A. L. "The Pathological Narcissism Inventory.” In J. S. Ogrodniczuk (Ed.), Understanding and treating pathological narcissism (pp. 93-110). Washington, DC, US: American Psychological Association, (2013). doi: 10.1037/14041-006.

[14] Eckert, M., D. D. Ebert, D. Lehr, B. Sieland, and M. Berking. "Overcome procrastination: Enhancing emotion regulation skills reduce procrastination.” Learning and Individual Differences 52, (2016): 10-18. doi: 10.1016/j.lindif.2016.10.001.

[15] Klingsieck, K. B. "Procrastination: When good things don't come to those who wait.” European Psychologist 18, no. 1 (2013): 24-34. doi: 10.1027/1016-9040/a000138.

[16] Rebetez, M. M. L., C. Barsics, L. Rochat, A. D'Argembeau, and M. Van der Linden. "Procrastination, consideration of future consequences, and episodic future thinking." Consciousness and Cognition 42, (2016): 286-292. doi: 10.1016/j.concog.2016.04.003.

[17] Ferrari, J. R., J. O'Callaghan, and I. Newbegin. "Prevalence of Procrastination in the United States, United Kingdom, and Australia: Arousal and Avoidance Delays among Adults.” North American Journal of Psychology 7, no. 1 (2005): 1-6.

[18] Ferrari, J. R., B. U. Özer, and A. Demir. "Chronic procrastination among Turkish adults: exploring decisional, avoidant, and arousal styles.” The Journal of Social Psychology 149, no. 3 (2009): 402-408. doi: 10.3200/SOCP.149.3.402-408.

[19] Schouwenburg, H. C. "Procrastination in Academic Settings: General Introduction.” In H. C. Schouwenburg, C. H. Lay, T. A. Pychyl, \& J. R. Ferrari (Eds.), Counseling the procrastinator in academic settings (pp. 3-17). Washington, DC, US: American Psychological Association, (2004). doi: 10.1037/10808-001.

[20] van Eerde, W. “A meta-analytically derived nomological network of procrastination.” Personality and Individual Differences 35, no. 6 (2003): 1401-1418. doi: 10.1016/S0191-8869(02)00358-6.

[21] Baumeister, R. F., T. F. Heatherton, and D. M. Tice. "Losing control: How and why people fail at self-regulation." San Diego, CA, US: Academic Press, (1994).

[22] Schouwenburg, H. C., and J. T. Groenewoud. "Study motivation under social temptation; effects of trait procrastination." Personality and Individual Differences 30, no. 2 (2001): 229-240. doi: 10.1016/S0191-8869(00)00034-9.

[23] Steel, P. "The nature of procrastination: A meta-analytic and theoretical review of quintessential self-regulatory failure." Psychological Bulletin 133, no. 1 (2007): 65-94. doi: 10.1037/0033-2909.133.1.65.

[24] Fernie, B. A., Z. Bharucha, A. V. Nikčević, C. Marino, and M. M. Spada. “A Metacognitive model of procrastination.” Journal of Affective Disorders 210, (2017): 196-203.

[25] Grunschel, C., J. Patrzek, and S. Fries. "Exploring different types of academic delayers: A latent profile analysis." Learning and Individual Differences 23, (2013): 225-233. doi: 10.1016/j.lindif.2012.09.014.

[26] Lukas, C. A., and M. Berking. "Reducing procrastination using a smartphone-based treatment program: A randomized controlled pilot study.” Internet Interventions 12, (2018): 83-90. doi: 10.1016/j.invent.2017.07.002.

[27] Fee, R. L., and J. P. Tangney. "Procrastination: A means of avoiding shame or guilt?" Journal of Social Behavior \& Personality 15 , no. 5 (2000): $167-184$.

[28] Stead, R., M. J. Shanahan, and R. W. J. Neufeld. "I'll go to therapy, eventually: Procrastination, stress and mental health." Personality and Individual Differences 49, no. 3 (2010): 175-180. doi: 10.1016/j.paid.2010.03.028.

[29] Klibert, J., J. Langhinrichsen-Rohling, A. Luna, and M. Robichaux. "Suicide proneness in college students: relationships with gender, procrastination, and achievement motivation.” Death Studies 35, no. 7 (2011): 625-645. doi: 10.1080/07481187.2011.553311.

[30] Rozental, A., and P. Carlbring. "Internet-based cognitive behavior therapy for procrastination: study protocol for a randomized controlled trial.” JMIR Research Protocols 2, no. 2 (2013): e46. doi: 10.2196/resprot.2801.

[31] Klassen, R. M., L. L. Krawchuk, and S. Rajani. “Academic procrastination of undergraduates: Low self-efficacy to self-regulate predicts higher levels of procrastination.” Contemporary Educational Psychology 33, no. 4 (2008): 915-931. doi: 10.1016/j.cedpsych.2007.07.001.

[32] Wäschle, K., A. Allgaier, A. Lachner, S. Fink, and M. Nückles. "Procrastination and self-efficacy: Tracing vicious and virtuous circles in self-regulated learning." Learning and Instruction 29, (2014): 103-114. doi: 10.1016/j.learninstruc.2013.09.005.

[33] Ferrari, J. R. "Dysfunctional procrastination and its relationship with self-esteem, interpersonal dependency, and self-defeating behaviors." Personality and Individual Differences 17, no. 5 (1994): 673-679. doi: 10.1016/0191-8869(94)90140-6.

[34] Brookes, J. "The effect of overt and covert narcissism on self-esteem and self-efficacy beyond self-esteem." Personality and Individual Differences 85, (2015): 172-175. doi: 10.1016/j.paid.2015.05.013.

[35] Butz, A. R., and E. L. Usher. "Salient sources of early adolescents' self-efficacy in two domains." Contemporary Educational 
Psychology 42, (2015): 49-61. doi: 10.1016/j.cedpsych.2015.04.001.

[36] Chesnut, S. R. "On the measurement of preservice teacher commitment: Examining the relationship between four operational definitions and self-efficacy beliefs.” Teaching and Teacher Education 68, (2017): 170-180. doi: 10.1016/j.tate.2017.09.003.

[37] Cuevas, C., K. T. Wolff, and M. T. Baglivio. "Self-efficacy, aspirations, and residential placement outcomes: Why belief in a prosocial self-matters." Journal of Criminal Justice 52, (2017): 1-11. doi: 10.1016/j.jcrimjus.2017.06.006.

[38] Bandura, A. "Self-efficacy: Toward a unifying theory of behavioral change." Psychological Review 84, no. 2 (1977): $191-215$. doi: 10.1037/0033-295X.84.2.191.

[39] Allred, S. L., L. D. Harrison, and D. J. O'Connell. "Self-efficacy: an important aspect of prison-based learning." The Prison Journal 93, no. 2 (2013): 211-233. doi: 10.1177/0032885512472964.

[40] Chesnut, S. R., and H. Burley. "Self-efficacy as a predictor of commitment to the teaching profession: A meta-analysis." Educational Research Review 15, (2015): 1-16. doi: 10.1016/j.edurev.2015.02.001.

[41] Bandura, A. "Self-efficacy determinants of anticipated fears and calamities." Journal of Personality and Social Psychology 45, no. 2 (1983): 464-469. doi: 10.1037/0022-3514.45.2.464.

[42] Bandura, A. "Perceived self-efficacy in cognitive development and functioning." Educational Psychologist 28, no. 2 (1993): 117-148. doi: 10.1207/s15326985ep2802_3.

[43] Bandura, A. "Self-efficacy mechanism in human agency." American Psychologist 37, no. 2 (1982): 122-147. doi: 10.1037/0003066X.37.2.122.

[44] Bandura, A. (Ed.). "Self-efficacy in changing societies." New York, NY, US: Cambridge University Press, (1995). doi: 10.1017/CBO9780511527692.

[45] Egan, S. J., T. D. Wade, and R. Shafran. "Perfectionism as a transdiagnostic process: A clinical review." Clinical Psychology Review 31, no. 2 (2011): 203-212. doi: 10.1016/j.cpr.2010.04.009.

[46] Flett, G. L., P. L. Hewitt, R. A. Davis, and S. B. Sherry. "Description and Counseling of the Perfectionistic Procrastinator.” In H. C. Schouwenburg, C. H. Lay, T. A. Pychyl, \& J. R. Ferrari (Eds.), Counseling the procrastinator in academic settings (pp. 181-194). Washington, DC, US: American Psychological Association, (2004). doi: 10.1037/10808-013.

[47] Sherry, S. B., J. Stoeber, and C. Ramasubbu. "Perfectionism explains variance in self-defeating behaviors beyond self-criticism: Evidence from a cross-national sample." Personality and Individual Differences 95, (2016): 196-199. doi: 10.1016/j.paid.2016.02.059.

[48] Smith, M. M., S. B. Sherry, D. H. Saklofske, and A. R. Mushqaush. "Clarifying the perfectionism-procrastination relationship using a 7-day, 14-occasion daily diary study." Personality and Individual Differences 112, (2017): 117-123. doi: 10.1016/j.paid.2017.02.059.

[49] Oddo-Sommerfeld, S., S. Hain, F. Louwen, and K. Schermelleh-Engel. "Longitudinal effects of dysfunctional perfectionism and avoidant personality style on postpartum mental disorders: Pathways through antepartum depression and anxiety." Journal of Affective Disorders 191, (2016): 280-288.

[50] Shim, S. S., L. D. Rubenstein, and C. W. Drapeau. "When perfectionism is coupled with low achievement: The effects on academic engagement and help seeking in middle school." Learning and Individual Differences 45, (2016): $237-244$. doi: 10.1016/j.lindif.2015.12.016.

[51] Stoeber, J., R. A. Harris, and P. S. Moon. "Perfectionism and the experience of pride, shame, and guilt: Comparing healthy perfectionists, unhealthy perfectionists, and non-perfectionists." Personality and Individual Differences 43, no. 1 (2007): 131141. doi: 10.1016/j.paid.2006.11.012.

[52] Hamachek, D. E. "Psychodynamics of normal and neurotic perfectionism." Psychology: A Journal of Human Behavior 15, no. 1 (1978): 27-33.

[53] Terry-Short, L. A., R. Glynn Owens, P. D. Slade, and M. E. Dewey. "Positive and negative perfectionism." Personality and Individual Differences 18, no. 5 (1995): 663-668. doi: 10.1016/0191-8869(94)00192-U.

[54] James, K., B. Verplanken, and K. A. Rimes. "Self-criticism as a mediator in the relationship between unhealthy perfectionism and distress." Personality and Individual Differences 79, (2015): 123-128. doi: 10.1016/j.paid.2015.01.030.

[55] Hill, R. W., T. J. Huelsman, and G. Araujo. "Perfectionistic concerns suppress associations between perfectionistic strivings and positive life outcomes." Personality and Individual Differences 48, no. 5 (2010): 584-589. doi: 10.1016/j.paid.2009.12.011.

[56] Stoeber, J. "Perfectionism in sport and dance: A double-edged sword." International Journal of Sport Psychology 45, no. 4 (2014): 385-394. Retrieved from https://kar.kent.ac.uk/41917/

[57] Howell, J. A., P. M. McEvoy, B. Grafton, C. Macleod, R. T. Kane, R. A. Anderson, and S. J. Egan. "Selective attention in 
perfectionism: Dissociating valence from perfectionism-relevance.” Journal of Behavior Therapy and Experimental Psychiatry 51, (2016): 100-108. doi: 10.1016/j.jbtep.2016.01.004.

[58] Gelabert, E., S. Subirà, L. García-Esteve, P. Navarro, A. Plaza, E. Cuyàs, R. Navinés, M. Gratacòs, M. Valdés, R. Martín-Santos. "Perfectionism dimensions in major postpartum depression." Journal of Affective Disorders 136, (2012): 17-25.

[59] Stoeber, J., and K. Otto. "Positive conceptions of perfectionism: Approaches, evidence, challenges.” Personality and Social Psychology Review 10, no. 4 (2006): 295-319. doi: 10.1207/s15327957pspr1004_2.

[60] Ames, D. R., P. Rose, and C. P. Anderson. “The NPI-16 as a short measure of narcissism.” Journal of Research in Personality 40, no. 4 (2006): 440-450. doi: 10.1016/j.jrp.2005.03.002.

[61] Mohammadzadeh, A. "Iranian validation of the narcissistic personality inventory-16 (Persian)." Journal of Fundamentals of Mental Health 11, no. 44 (2010): 274-281.

[62] Lay, C. H. “At last, my research article on procrastination.” Journal of Research in Personality 20, no. 4 (1986): $474-495$. doi: 10.1016/0092-6566(86)90127-3.

[63] Ferrari, J. R. "Reliability of academic and dispositional measure of procrastination." Psychological Reports 64, no. 3 (1989): $1057-1058$.

[64] Ferrari, J. R., J. L. Johnson, and W. G. McCown. "The Plenum series in social/clinical psychology. Procrastination and task avoidance: Theory, research, and treatment.” New York, NY, US: Plenum Press, (1995). doi: 10.1007/978-1-4899-0227-6.

[65] Hosseini, F., and M. Khayyer. "Prediction of Behavioral and Decisional Procrastination Considering Meta-Cognition Beliefs in University Students (Persian).” Iranian Journal of Psychiatry and Clinical Psychology 15, no. 3 (2009): 265-273.

[66] Schwarzer, R., and M. Jerusalem. "Generalized Self-Efficacy scale.” In J. Weinman, S. Wright, \& M. Johnston, Measures in health psychology: A user's portfolio. Causal and control beliefs (pp. 35-37). Windsor, UK: NFER-NELSON, (1995).

[67] Nezami, E., R. Schwarzer, and M. Jerusalem. "Persian Adaptation (Farsi) of the General Self-Efficacy Scale.” (1996). Retrieved from http://userpage.fu-berlin.de/ health/persean.htm

[68] Schwarzer, R., J. Bäßler, P. Kwiatek, K. Schröder, and J. X. Zhang. "The assessment of optimistic self-beliefs: Comparison of the German, Spanish, and Chinese versions of the General Self-efficacy Scale.” Applied Psychology: An International Review 46, no. 1 (1997): 69-88. doi: 10.1111/j.1464-0597.1997.tb01096.x.

[69] Rajabi, G. R. "Reliability and validity of the General Self-Efficacy Beliefs Scale (GSE-10) comparing the psychology students of Shahid Chamrin University and Azad University of Marvdasht (Persian)." New Thoughts on Education 2, no. 1-2 (2006): $111-122$.

[70] Goldberg, D. P. "The detection of psychiatric illness by questionnaire: A technique for the identification and assessment of nonpsychotic psychiatric illness.” Oxford, England: Oxford U. Press, (1972).

[71] Coopersmith, S. “The antecedents of self-esteem.” San Francisco, CA, US: W. H. Freeman, (1967).

[72] Besharat, M. A. "Relation of positive and negative perfectionism with defense mechanisms (Persian)." Psychological Research 8, no. 1-2 (2005): 7-22.

[73] Caprara, G. V., R. Fida, M. Vecchione, G. Del Bove, G. M. Vecchio, C. Barbaranelli, and A. Bandura. "Longitudinal analysis of the role of perceived self-efficacy for self-regulated learning in academic continuance and achievement." Journal of Educational Psychology 100, no. 3 (2008): 525-534. doi: 10.1037/0022-0663.100.3.525.

[74] Sirois, F. M. "Procrastination and intentions to perform health behaviors: The role of self-efficacy and the consideration of future consequences." Personality and Individual Differences 37, no. 1 (2004): 115-128. doi: 10.1016/j.paid.2003.08.005.

[75] Mann, M. P. "The adverse influence of narcissistic injury and perfectionism on college students' institutional attachment." Personality and Individual Differences 36, no. 8 (2004): 1797-1806. doi: 10.1016/j.paid.2003.07.001.

[76] Ronningstam, E., and A. R. Baskin-Sommers. "Fear and decision-making in narcissistic personality disorder-a link between psychoanalysis and neuroscience." Dialogues in Clinical Neuroscience 15, no. 2 (2013): 191-201. Retrieved from https://www.ncbi.nlm.nih.gov/pmc/articles/PMC3811090/

[77] Sigall, H., A. Kruglanski, and J. Fyock. "Wishful thinking and procrastination.” Journal of Social Behavior \& Personality 15, no. 5 (2000): 283-296.

[78] Schouwenburg, H. C., and C. H. Lay. “Trait procrastination and the Big Five factors of personality.” Personality and Individual Differences 18, no. 4 (1995): 481-490. doi: 10.1016/0191-8869(94)00176-S.

[79] Ronningstam, E. "Intersect between self-esteem and emotion regulation in narcissistic personality disorder - implications for alliance building and treatment." Borderline Personality Disorder and Emotion Dysregulation 4, no. 3 (2017). doi: 10.1186/s40479-017-0054-8. 


\section{9- Appendix}

\section{9-1- Narcissistic Personality Inventory-16 (NPI-16)}

Read each pair of statements below and place an " $\mathrm{X}$ " by the one that comes closest to describing your feelings and beliefs about yourself. You may feel that neither statement describes you well, but pick the one that comes closest. Please complete all pairs.

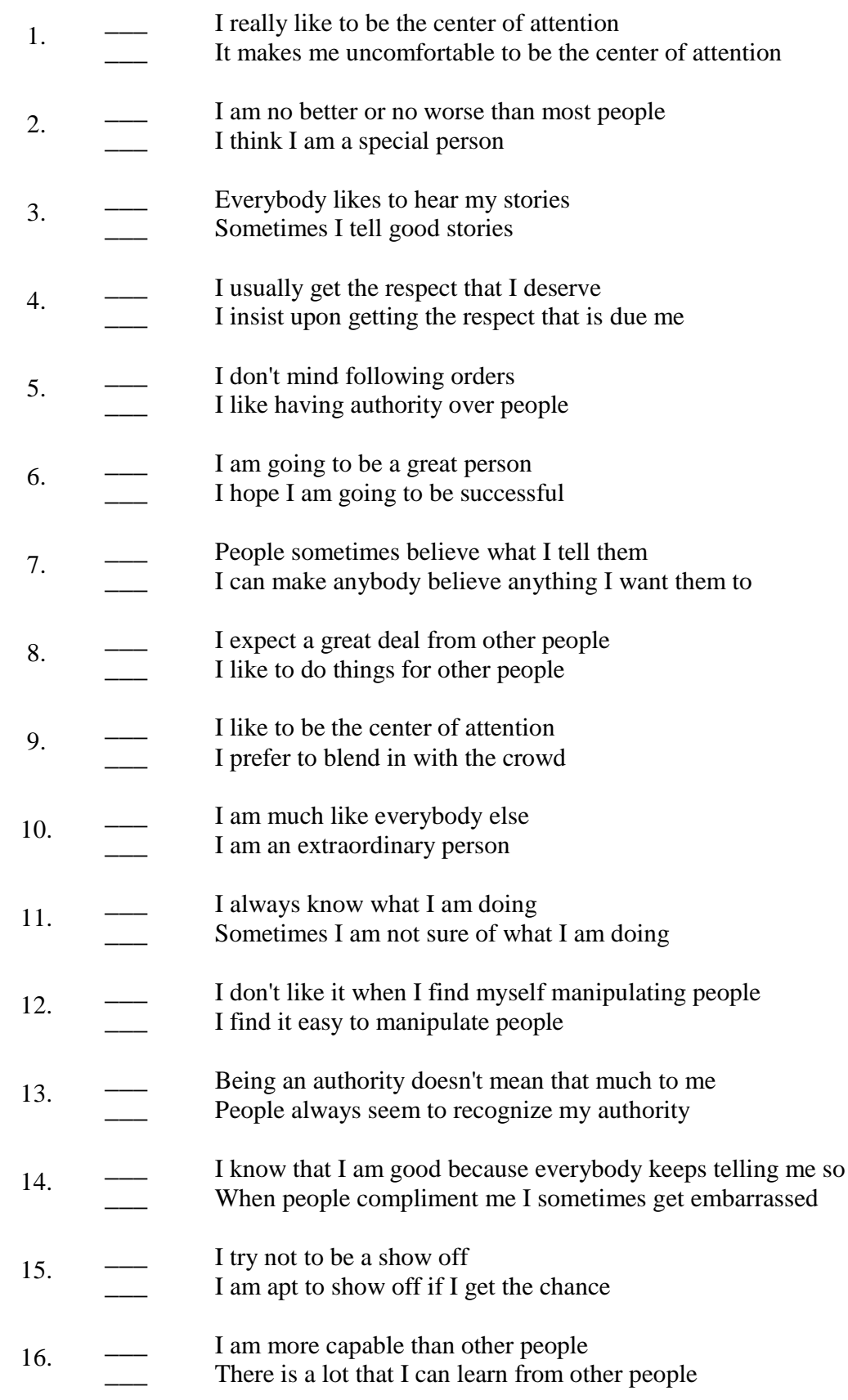

\section{9-2- General Procrastination Scale (GPS) - For student populations}

People may use the following statements to describe themselves. For each statement, decide whether the statement is 'uncharacteristic' or 'characteristic' of you using the following 5 point scale. Note that the 3 on the scale is Neutral - the statement is neither characteristic nor uncharacteristic of you. In the box to the right of each statement, fill in the number on the 5 point scale that best describes you. 


$\begin{array}{ccccc}\text { Extremely } & \text { Moderately } & \text { Neutral } & \text { Moderately } & \text { Extremely } \\ \text { Uncharacteristic } & \text { Uncharacteristic } & 3 & 4 & \text { Characteristic }\end{array}$

1. I often find myself performing tasks that I had intended to do days before.

2. I do not do assignments until just before they are to be handed in.

3. When I am finished with a library book, I return it right away regardless of the date it is due.

4. When it is time to get up in the morning, I most often get right out of bed.

5. A letter may sit for days after I write it before mailing it.

6. I generally return phone calls promptly.

7. Even with jobs that require little else except sitting down and doing them, I find they seldom get done for days.

8. I usually make decisions as soon as possible.

9. I generally delay before starting on work I have to do.

10. I usually have to rush to complete a task on time.

11. When preparing to go out, I am seldom caught having to do something at the last minute.

12. In preparing for some deadline, I often waste time by doing other things.

13. I prefer to leave early for an appointment.

14. I usually start an assignment shortly after it is assigned.

15. I often have a task finished sooner than necessary.

16. I always seem to end up shopping for birthday or Christmas gifts at the last minute.

17. I usually buy even an essential item at the last minute.

18. I usually accomplish all the things I plan to do in a day.

19. I am continually saying "I'll do it tomorrow".

20. I usually take care of all the tasks I have to do before I settle down and relax for the evening.

\section{9-3- General Self-Efficacy Scale (GSE-10)}

Please read the following statements carefully. For each statement, decide whether the statement is 'not at all true' or 'true' of you using the following 4 point scale. In the box to the right of each statement, fill in the number on the 4 point scale that best describes you.

$\begin{array}{cccc}\text { Not at All True } & \text { Hardly True } & \text { Moderately True } & \text { Exactly True }\end{array}$

1. I can always manage to solve difficult problems if I try hard enough.

2. If someone opposes me, I can find the means and ways to get what I want.

3. It is easy for me to stick to my aims and accomplish my goals.

4. I am confident that I could deal efficiently with unexpected events.

5. Thanks to my resourcefulness, I know how to handle unforeseen situations.

6. I can solve most problems if I invest the necessary effort.

7. I can remain calm when facing difficulties because I can rely on my coping abilities.

8. When I am confronted with a problem, I can usually find several solutions.

9. If I am in trouble, I can usually think of a solution.

10. I can usually handle whatever comes my way. 


\section{9-4- Positive and Negative Perfectionism Scale (PANPS)}

Please read the following statements carefully. For each statement, decide whether the statement is 'strongly disagree' or 'strongly agree' of you using the following 5 point scale. In the box to the right of each statement, fill in the number on the 5 point scale that best describes you.

Strongly Disagree

Disagree

2
Don't Know 3 $\underset{4}{\text { Agree }}$
Strongly Agree 5

1. When I start something I feel anxious that I might fail.

2. My family and friends are proud of me when I do really well.

3. I take pride in being meticulous when doing things.

4. I set impossibly high standards for myself.

5. I try to avoid the disapproval of others at all costs.

6. I like the acclaim I get for an outstanding performance.

7. When I am doing something I cannot relax until it's perfect.

8. It feels as though my best is never good enough for other people.

9. Producing a perfect performance is a reward in its own right.

10. The problem of success is that I must work even harder.

11. If I make a mistake I feel that the whole thing is ruined.

12. I feel dissatisfied with myself unless I am working towards a higher standard all the time.

13. I know the kind of person I ought or want to be, but feel I always fall short of this.

14. Other people respect me for my achievements.

15. As a child however well I did, it never seemed good enough to please my parents.

16. I think everyone loves a winner.

17. Other people expect nothing less than perfection of me.

18. When I'm competing against others, I'm motivated by wanting to be the best.

19. I feel good when pushing out the limits.

20. When I achieve my goals I feel dissatisfied.

21. My high standards are admired by others.

22. If I fail people, I fear they will cease to respect or care for me.

23. I like to please other people by being successful.

24. I gain great approval from others by the quality of my accomplishments.

25. My successes spur me on to greater achievements.

26. I feel guilty or ashamed if I do less than perfectly.

27. No matter how well I do I never feel satisfied with my performance.

28. I believe that rigorous practice makes for perfection.

29. I enjoy the glory gained by successes.

30. I gain deep satisfaction when I have perfected something.

31. I feel I have to be perfect to gain people's approval.

32. My parents encouraged me to excel.

33. I worry what others think if I make mistakes.

34. I get fulfilment from totally dedicating myself to a task.

35. I like it when others recognize that what I do requires great skill and effort to perfect.

36. The better I do, the better I am expected to do by others.

37. I enjoy working towards greater levels of precision and accuracy.

38. I would rather not start something than risk doing it less than perfectly.

39. When I do things I feel others will judge critically the standard of my work.

40. I like the challenge of setting very high standards for myself. 